\title{
VOLUME DE MADEIRA E CONCENTRAÇÃO FOLIAR DE NUTRIENTES EM PARCELAS EXPERIMENTAIS DE Eucalyptus grandis FERTILIZADAS COM LODOS DE ESGOTO ÚMIDO E SECO ${ }^{1}$
}

Paulo Henrique Muller da Silva ${ }^{2}$, Fábio Poggiani ${ }^{3}$ José Leonardo de Moraes Gonçalves e José Luiz Stape $^{3}$

\begin{abstract}
RESUMO - No Brasil, diversos municípios estão construindo estações de tratamento de esgoto (ETEs), e futuramente serão produzidas anualmente milhares de toneladas de lodo para as quais deverá ser dada destinação adequada. O lodo de esgoto tratado (biossólido) é o resíduo resultante do tratamento do esgoto urbano, e sua disposição final precisa ser bem planejada devido às implicações sanitárias, ambientais, econômicas e sociais. Apresenta elevado teor de matéria orgânica e de nutrientes e poderia ser utilizado como fertilizante em plantios florestais. Esta pesquisa foi realizada na Estação de Ciências Florestais de Itatinga (Universidade de São Paulo), com o objetivo de avaliar o efeito da adição de três doses $\left(10,20\right.$ e $\left.30 \mathrm{t} \mathrm{ha}^{-1}\right)$ dos lodos de esgoto úmido (torta) e seco (granulado), complementados com K e B e aplicados ao solo nas linhas de plantio em parcelas experimentais de Eucalyptus grandis. Dezoito meses após a implantação das mudas no campo, o volume dos troncos demonstrou aumento significativo (ao redor de 130\%) no tocante ao crescimento dos eucaliptos tratados com os biossólidos úmido e seco em relação à testemunha sem aplicação de fertilizante, bem como teve resultado semelhante ao do tratamento com adubo mineral. Entretanto, não houve diferença significativa entre os tratamentos com a aplicação dos biossólidos úmido e seco. Com relação à nutrição mineral, foi observado aumento da concentração dos elementos $\mathrm{P}$, Ca e $\mathrm{Zn}$ nas folhas com as maiores doses dos biossólidos, e verificou-se efeito inverso de Mn. As concentrações foliares de todos os nutrientes nos eucaliptos tratados com os biossólidos mantiveram-se dentro dos limites observados usualmente nas plantações comerciais, não havendo sinais de desequilíbrio nutricional.
\end{abstract}

Palavras-chave: Lodo de esgoto, biossólido e nutrição foliar.

\section{WOOD VOLUME AND FOLIAR CONCENTRATION OF NUTRIENTS IN Eucalyptus grandis AFTER WET AND DRY SEWAGE SLUDGE APPLICATION}

\begin{abstract}
In Brazil, several municipalities are building waste treatment plants and in the future thousands of tons of sewage sludge will be generated. Sewage sludge is the waste left over after wastewater treatment and its disposal needs to be well planned, considering sanitary, environmental, economic and social implications. Sewage sludge (biosolids) is high in organic content and plant nutrient and could be applied as fertilizer in forest plantations. The aim of this research, conducted at the Experimental Station of Itatinga (University of São Paulo) was to evaluate the effects of increasing doses (10, 20 and 30 tons ha ${ }^{-1}$ ) of wet and dry biosolids(pellets), complemented with $K$ and $B$, and applied to planting rows in experimental Eucalyptus grandis plots 1.5 years after seedling plantation. Trunk volume increased significantly regarding the eucalypt trees that received wet and dry sewage sludge, compared to the control treatment (no fertilization), and a similar growth of eucalypt trees that received full mineral fertilization. Regarding mineral nutrition, a positive correlation was
\end{abstract}

\footnotetext{
${ }^{1}$ Recebido em 05.04.2007 e aceito para publicação em 22.08.2008.

${ }^{2}$ Instituto de Pesquisas e Estudos Florestais (IPEF). E-mail:<paulohenrique @ ipef.br>.

${ }^{3}$ Departamento de Ciências Florestais da Escola Superior de Agricultura "Luiz de Queiroz (ESALQ). E-mail:<fpoggian@esalq.usp.br>
} 
observed between doses of biosolids and $\mathrm{P}, \mathrm{Ca}$, and $\mathrm{Zn}$ concentrations in the leaves, but a negative effect for Mn and biosolid dose. The foliar concentration of all the nutrients in the biosolid-treated eucalypt trees remained within the limits observed in commercial plantations, with no signs of nutritional imbalance.

Keywords: Sewage sludge, biosolids and foliar nutrition.

\section{INTRODUÇÃO}

O lodo é o resíduo do tratamento do esgoto levado às Estações de Tratamento de Esgoto (ETEs) através da rede coletora urbana. $O$ processo de retirada da fração sólida do esgoto, que varia entre 1 e $2 \%$ do volume total, pode corresponder até $40 \%$ do custo operacional da estação de tratamento (TSUTIYA, 2000). O lodo produzido no tratamento de esgoto pode ter diferentes alternativas de disposição, como aterro sanitário, incineração e sua aplicação em sistemas agroflorestais. Seu uso em plantios florestais, visando melhorar a fertilidade do solo e manter o estoque de nutrientes no ecossistema, poderia ser uma nova opção ecológica e economicamente interessante (FORSTER et al., 1977).

O potencial agronômico do lodo é inquestionável, mas sua utilização em áreas agrícolas produtivas deve ocorrer de maneira cuidadosa, de modo a não provocar danos à saúde pública e ao meio ambiente ou prejuízos financeiros ao agricultor (LUDUVICE, 2000). Um dos métodos para melhorar a qualidade de solos pobres seriam a adição de matéria orgânica e o uso de lodo de esgoto para favorecer o crescimento das plantas, além de ser excelente alternativa para a disposição desse resíduo urbano (SELIVANOVSKAYA et al., 2003). O lodo é uma fonte orgânica de nutrientes, entretanto os metais pesados, eventualmente presentes, podem acumular-se no solo depois de repetidas aplicações e, dependendo das concentrações, gerar impactos indesejáveis sobre os microrganismos, as plantas e os animais (FJÄLLBORG et al., 2005). Para a utilização do lodo proveniente das estações de tratamento sanitário do esgoto em plantações florestais, deve-se realizar o processamento correto, de modo a permitir seu manuseio de forma segura. Rocha (2002) observou que a fertilidade do solo em plantio de Eucalyptus grandis elevou-se gradualmente depois da aplicação do lodo de esgoto e que as árvores responderam positivamente com maiores ganhos de produtividade em relação à adubação convencional. A resposta positiva à aplicação do lodo de esgoto em plantios de eucaliptos aumentou ao longo do tempo, refletindo os efeitos da disponibilização dos nutrientes para as árvores, através da decomposição do lodo aplicado (VAZ, 2000).
Mcnab e Bery (1985), estudando a aplicação de lodo de esgoto em plantio de diferentes espécies de Pinus em solos degradados dos EUA, observaram que o tratamento com a aplicação de lodo obteve maior incremento em relação ao tratamento com adubação mineral. A aplicação do lodo pode aumentar significativamente os retornos econômicos de uma plantação florestal devido à maior produtividade obtida, compensando os custos de transporte e aplicação do resíduo (KIMBERLEY et al., 2004). Guedes (2005) estudou a aplicação de biossólido, tratado com cal e cloreto férrico, nas entrelinhas de plantio em uma área experimental de Eucalyptus grandis. Observou efeitos positivos no crescimento graças à aplicação do lodo, que serviu como fonte de nutrientes. Mas, por ter sido o lodo aplicado nas entrelinhas dos eucaliptos, a resposta sobre o crescimento das plantas ocorreu quase um ano após o plantio. O lodo de esgoto tem vantagem em relação à adubação mineral, pois libera lentamente os nutrientes para o sistema radicular das árvores. Dessa forma, nas culturas de ciclo longo, plantadas em solos arenosos e de baixa fertilidade, a lenta liberação dos nutrientes pode otimizar sua absorção através do sistema radicular e reduzir a lixiviação (POGGIANI et al., 2000).

Para aprimorar o tratamento do lodo de esgoto e viabilizar sua disposição em aterros sanitários, bem como na agricultura, a SABESP, a partir de 2002, deu início ao procedimento do uso de polímeros para condicionamento do lodo, seguido de secagem térmica, produzindo biossólido seco (granulado). O lodo seco e granulado oferece diversas vantagens em relação ao lodo úmido, visto que, além de ser completamente isento de patógenos, torna-se mais econômico seu transporte e tecnicamente mais operacional sua distribuição no campo. Não existindo pesquisas a respeito da utilização de lodo de esgoto seco termicamente em plantações florestais, foi objetivo deste ensaio avaliar comparativamente a influência da aplicação nas linhas de plantio de doses crescentes dos lodos úmido (torta) e seco (granulado) sobre o crescimento das árvores de Eucalyptus grandis, bem como o seu reflexo na variação dos teores de macro e micronutrientes nas folhas, aos 18 meses de idade. 


\section{MATERIAL E METODOS}

\subsection{Descrição da área experimental}

O experimento foi implantado na Estação Experimental de Ciências Florestais de Itatinga, vinculada à Escola Superior de Agricultura Luiz de Queiroz, da Universidade de São Paulo, localizada no Município de Itatinga, SP, a $23^{\circ} 02^{\prime}$ de latitude Sul e $48^{\circ} 37^{\prime}$ de longitude Oeste de Greenwich e com altitude média de $830 \mathrm{~m}$.

O clima do Município de Itatinga é do tipo mesotérmico úmido, segundo a classificação de Köppen. A precipitação média anual é de $1.500 \mathrm{~mm}$, a temperatura média anual de $19,4{ }^{\circ} \mathrm{C}$ e a umidade relativa gira ao redor de $80 \%$. A precipitação média mensal do mês mais seco varia entre 30 e $60 \mathrm{~mm}$.

O solo da área experimental é um Latossolo Vermelho-Amarelo com textura médio-arenosa, suavemente ondulado e de baixa fertilidade natural (Tabela 1). Apresenta pH ácido, ao redor de 4, e baixos teores de macro e micronutrientes. A vegetação natural primitiva era constituída principalmente por plantas de Cerrado. O Município de Itatinga é uma das áreas mais representativas, onde se pratica a silvicultura intensiva do eucalipto no Estado de São Paulo.

\subsection{Delineamento experimental e tratamentos}

O experimento foi implantado em abril de 2003, com oito tratamentos distribuídos de forma casualizada em três blocos, definidos em função da declividade, que é de aproximadamente 5\%. Cada parcela, constituída por oito linhas de plantio, possui uma superfície de $384 \mathrm{~m}^{2}$ (24 x $\left.16 \mathrm{~m}\right)$. Nas linhas de plantio, as mudas de Eucalyptus grandis foram espaçadas em $2 \mathrm{~m}$ e nas entrelinhas em $3 \mathrm{~m}$, totalizando 64 plantas por parcela. Como área útil da parcela, foram consideradas apenas as 36 plantas centrais, descontando-se a bordadura simples, totalizando uma área efetiva de amostragem de $216 \mathrm{~m}^{2}$ por parcela. O preparo de solo foi realizado no sistema de cultivo mínimo, com subsolagem na linha de plantio até $45 \mathrm{~cm}$ de profundidade. Esta é a metodologia mais utilizada nas empresas florestais e foi utilizada no experimento, pois o preparo de solo tem grande importância no desenvolvimento das espécies florestais (GATTO et al., 2003).

Os tratamentos foram constituídos pela adição ao solo de doses crescentes de lodo de esgoto, calculadas em base seca a partir das concentrações observadas nos respectivos lodos úmido (torta) e seco (granulado), conforme expresso nas Tabelas 2 e 3 . A aplicação do lodo de esgoto foi efetuada nas linhas de plantio, uma semana após a implantação das mudas.

i) Testemunha - sem adubação e sem aplicação de lodo de esgoto.

ii) 10 úmido $-10 \mathrm{tha}^{-1}$ de lodo de esgoto úmido com complementação de potássio e boro.

iii) $10 \mathrm{seco}-10 \mathrm{t} \mathrm{ha}^{-1}$ de lodo de esgoto seco com complementação de potássio e boro.

iv) 20 úmido - $20 \mathrm{t} \mathrm{ha}^{-1}$ de lodo de esgoto úmido com complementação de potássio e boro.

v) $20 \mathrm{seco}-20 \mathrm{t} \mathrm{ha}^{-1}$ de lodo de esgoto seco com complementação de potássio e boro.

vi) 30 úmido - $30 \mathrm{t} \mathrm{ha}^{-1}$ de lodo de esgoto úmido com complementação de potássio e boro.

vii) 30 seco $-30 \mathrm{t} \mathrm{ha}^{-1}$ de lodo de esgoto seco com complementação de potássio e boro.

vii) Ad. mineral - Foi aplicado o adubo mineral utilizado normalmente pelas empresas florestais da região, constituído por 1,5 tha-1 de calcário dolomítico (a lanço, em área total), $110 \mathrm{~kg} \mathrm{ha}^{-1}$ de 0-45-0 (no sulco de plantio), $150 \mathrm{~kg} \mathrm{ha}^{-1}$ de 10-20-10 (no sulco de plantio), $80 \mathrm{~kg}$ ha $^{-1}$ de 20-0-20 (45 dias pós-plantio, aplicado em meialua ao redor da muda), $180 \mathrm{~kg} \mathrm{ha}^{-1}$ de $16-0-32+0,3 \%$ de $\mathrm{B}+0,5 \%$ de $\mathrm{Zn}$ ( 6 meses pós-plantio, aplicado numa faixa contínua na entrelinha de plantio) e $240 \mathrm{~kg} \mathrm{ha}^{-1} \mathrm{de}$ 16-0-32 + 0,3\% de B + 0,5\% de Zn (12 meses pósplantio, aplicado numa faixa contínua na entrelinha de plantio).

Tabela 1 - Análise do solo antes da implantação da área experimental Table 1 - Soil analysis before planting experimental area

\begin{tabular}{|c|c|c|c|c|c|c|c|c|c|c|c|c|c|c|c|c|c|c|}
\hline \multirow[t]{2}{*}{ Prof. } & $\mathrm{P}$ & M.O. & $\mathrm{pH}$ & $\mathrm{K}$ & $\mathrm{Ca}$ & $\mathrm{Mg}$ & $\mathrm{H}+\mathrm{Al}$ & $\mathrm{Al}$ & \multirow[t]{2}{*}{ SB } & \multirow[t]{2}{*}{$\mathrm{T}$} & \multirow{2}{*}{$\begin{array}{l}\mathrm{V} \\
\% \\
\end{array}$} & \multirow{2}{*}{$\begin{array}{l}\text { Sat. } \\
\mathrm{Al}^{3+}\end{array}$} & $\mathrm{S}-\mathrm{SO}_{4}{ }^{2-}$ & $\mathrm{B}$ & $\mathrm{Cu}$ & $\mathrm{Fe}$ & $\mathrm{Mn}$ & \multirow[t]{2}{*}{$\mathrm{Zn}$} \\
\hline & $\mathrm{g} \mathrm{dm}^{-3}$ & $\mathrm{~g} \mathrm{dm}^{-3}$ & $\mathrm{CaCl}_{2}$ & \multicolumn{5}{|c|}{$\mathrm{mmolc} \mathrm{dm}^{-3}$} & & & & & \multicolumn{5}{|c|}{$\mathrm{mg} \mathrm{dm}^{-3}$} & \\
\hline $0-5$ & 9 & 26 & 4 & 0,7 & 5 & 4 & 71 & 27 & 10 & 82 & 12 & 75 & 24 & 0,25 & 0,5 & 104 & 2,5 & 0,8 \\
\hline $5-10$ & 6 & 17 & 4 & 0,6 & 3 & 2 & 57 & 24 & 5 & 63 & 8 & 84 & 30 & 0,21 & 0,6 & 76 & 1,1 & 0,4 \\
\hline $10-20$ & 7 & 13 & 4 & 0,6 & 2 & 2 & 44 & 20 & 4 & 51 & 9 & 82 & 34 & 0,19 & 0,7 & 55 & 0,6 & 0,3 \\
\hline
\end{tabular}


Tabela 2 - Análise química dos lodos úmido (torta) e seco (granulado) produzidos pela SABESP

Table 2 - Chemical analysis of wet and dry sludge produced by SABESP

\begin{tabular}{|c|c|c|}
\hline Determinações & $\begin{array}{l}\text { Lodo } \\
\text { úmido }\end{array}$ & $\begin{array}{l}\text { Lodo } \\
\text { seco }\end{array}$ \\
\hline $\mathrm{pH}$ em $\mathrm{CaCl}_{2} 0,01 \mathrm{M}$ & 7,3 & 6,5 \\
\hline Densidade & $1,03 \mathrm{~g} \mathrm{~cm}^{-3}$ & $0,97 \mathrm{~g} \mathrm{~cm}^{-3}$ \\
\hline Umidade perdida a $60-65^{\circ} \mathrm{C}$ & $76,04 \%$ & $4,14 \%$ \\
\hline Umidade perdida entre 65 e $110^{\circ} \mathrm{C}$ & $1,32 \%$ & $3,29 \%$ \\
\hline Umidade Total & $77,36 \%$ & $7,43 \%$ \\
\hline Matéria Orgânica Total (combustão) & $54,64 \%$ & $53,02 \%$ \\
\hline Matéria Orgânica compostável & $52,52 \%$ & $50,20 \%$ \\
\hline $\begin{array}{l}\text { Mat. Orgânica resistente } \\
\text { a compostagem }\end{array}$ & $2,12 \%$ & $2,82 \%$ \\
\hline Carbono Total (orgânico e mineral) & $30,79 \%$ & $29,45 \%$ \\
\hline Carbono Orgânico & $29,20 \%$ & $27,88 \%$ \\
\hline Resíduo Mineral Total & $45,36 \%$ & $46,88 \%$ \\
\hline Resíduo Mineral Insolúvel & $20,89 \%$ & $22,45 \%$ \\
\hline Resíduo Mineral Solúvel & $24,47 \%$ & $24,43 \%$ \\
\hline Nitrogênio Total & $3,27 \%$ & $3,47 \%$ \\
\hline Fósforo $\left(\mathrm{P}_{2} \mathrm{O}_{5}\right)$ & $3,27 \%$ & $3,84 \%$ \\
\hline Potássio $\left(\mathrm{K}_{2} \mathrm{O}\right)$ total & $0,27 \%$ & $0,27 \%$ \\
\hline Cálcio (Ca) Total & $2,52 \%$ & $2,46 \%$ \\
\hline Magnésio (Mg) Total & $0,49 \%$ & $0,39 \%$ \\
\hline Enxofre (S) Total & $0,66 \%$ & $0,68 \%$ \\
\hline Relação C/N (C total e $\mathrm{N}$ total) & 9,4 & 8,5 \\
\hline Relação C/N (C orgânico e $N$ total) & 8,9 & 7,3 \\
\hline Cobre $(\mathrm{Cu})$ Total & $0,057 \%$ & $0,07 \%$ \\
\hline Manganês (Mn) Total & $0,0194 \%$ & $0,030 \%$ \\
\hline Zinco $(\mathrm{Zn})$ Total & $0,238 \%$ & $0,32 \%$ \\
\hline Ferro $(\mathrm{Fe})$ Total & $3,90 \%$ & $4,52 \%$ \\
\hline Boro (B) Total & $0,0009 \%$ & $0,0002 \%$ \\
\hline Sódio (Na) Total & $0,0583 \%$ & $0,09 \%$ \\
\hline
\end{tabular}

A complementação de potássio ( $\mathrm{KCl})$ e boro (Bórax) nos tratamentos com os biossólidos foi necessária em razão dos baixos teores desses elementos no lodo de esgoto (Tabela 2), bem como no solo. Esses nutrientes foram adicionados, portanto, até atingirem valores iguais aos do tratamento com adubação mineral. A aplicação dos diferentes lodos (seco e úmido) e da adubação mineral propiciou adição considerável de nutrientes ao solo (Tabela 3 ).

\subsection{Avaliação do incremento volumétrico dos eucaliptos}

Aos 18 meses de idade foram realizadas as medições de altura e DAP (diâmetro à altura do peito) das árvores nas áreas úteis de todas as parcelas dos três blocos do experimento, totalizando 36 árvores por parcela. Para a medição de altura, utilizou-se o hipsômetro "Blume-liees" e para a medição do DAP, uma fita métrica.

R. Árvore, Viçosa-MG, v.32, n.5, p.845-854, 2008
Na determinação do volume individual das árvores foi utilizada a equação $\mathrm{Vol}=1,7 \times 10^{-5} \times D A P^{1,9117} \times H T^{1,3065}$, obtida por Guedes (2005) em trabalho realizado na Estação Experimental de Itatinga, onde também foi avaliado o crescimento do Eucalyptus grandis, após a aplicação de biossólido nas entrelinhas de plantio.

\subsection{Determinação da concentração de nutrientes nas folhas dos eucaliptos}

Aos 18 meses de idade, foram coletadas amostras de folhas do terço superior das copas de oito árvores médias existentes dentro da área útil das parcelas (repetições) de cada tratamento, constituindo três amostras compostas destinadas à análise dos macro e micronutrientes, totalizando 24 amostras. Depois de coletadas, as amostras de folhas foram secas em estufa a $65^{\circ} \mathrm{C}$, até atingirem peso constante e moídas em moinho tipo Willey (peneira de 20 mesh). Com relação aos elementos N, P, K, Ca, Mg, S, Fe, Cu, Mn, Zn e B, as análises químicas foram realizadas no Laboratório de Ecologia Aplicada do Departamento de Ciências Florestais da ESALQ, após a digestão sulfúrica do nitrogênio, digestão seca do boro e digestão perclórica dos demais elementos. $\mathrm{O} \mathrm{N}$ foi determinado pelo método microKjedhal, os elementos $\mathrm{P}$ e o B foram determinados por colorimetria, o K por fotometria de chama e o $\mathrm{S}$ por turbidimetria. $\mathrm{Ca}, \mathrm{Mg}, \mathrm{Fe}, \mathrm{Cu}, \mathrm{Mn}$ e $\mathrm{Zn}$ foram determinados por espectrofotometria de absorção atômica, conforme procedimento indicado por Malavolta et al. (1997).

\subsection{Analise Estatística}

Os dados foram submetidos à análise de variância. Nos casos que apresentaram diferenças a $5 \%$ de probabilidade, foi utilizado o teste de Duncan.

\section{RESULTADOS E DISCUSSÃO}

\subsection{Efeito das doses crescentes de biossólidos no volume de madeira produzido}

Os resultados do volume de madeira no $18^{\circ}$ mês pós-plantio (Figura 1) evidenciaram que os tratamentos com aplicação dos lodos foram significativamente superiores ao do tratamento-testemunha e estatisticamente iguais ao do tratamento com adubação mineral. Não se observou diferença estatística entre os tratamentos com as doses crescentes aplicadas e também entre os dois tipos de lodo (úmido e seco). Contudo, esses resultados devem ser considerados ainda iniciais, visto que o ciclo de corte previsto para o talhão experimental é de aproximadamente seis anos. 
Tabela 3 - Nutrientes adicionados ao solo em cada tratamento, através de aplicação dos lodos de esgoto úmido e seco Table 3 - Nutrients added to the soil through application of the wet and dry sludge

\begin{tabular}{|c|c|c|c|c|c|c|c|c|c|c|c|c|}
\hline Tratamentos & $\mathrm{N}$ & $\mathrm{P}_{2} \mathrm{O}_{5}$ & $\mathrm{~K}_{2} \mathrm{O} *$ & $\mathrm{Ca}$ & $\mathrm{Mg}$ & $\mathrm{S}$ & $\mathrm{B}^{*}$ & $\mathrm{Zn}$ & $\mathrm{Fe}$ & $\mathrm{Cu}$ & $\mathrm{Mn}$ & $\mathrm{Na}$ \\
\hline \multicolumn{13}{|c|}{$\mathrm{kg} \mathrm{ha}^{-1}$} \\
\hline Testemunha & - & - & - & - & - & - & - & - & - & - & - & - \\
\hline 10 úmido & 327 & 327 & 160 & 252 & 49 & 66 & 1,26 & 23,8 & 390 & 5,7 & 1,9 & 5,8 \\
\hline 10 seco & 347 & 384 & 160 & 246 & 39 & 68 & 1,26 & 32,2 & 452 & 7,0 & 3,0 & 9,0 \\
\hline 20 úmido & 654 & 654 & 160 & 504 & 97 & 133 & 1,26 & 47,6 & 780 & 11,4 & 3,9 & 11,6 \\
\hline 20 seco & 695 & 768 & 160 & 492 & 78 & 136 & 1,26 & 64,4 & 904 & 14,0 & 6,0 & 18,0 \\
\hline 30 úmido & 981 & 981 & 160 & 755 & 146 & 199 & 1,26 & 71,4 & 1170 & 17,1 & 5,8 & 17,4 \\
\hline 30 seco & 1042 & 1152 & 160 & 738 & 117 & 204 & 1,26 & 96,6 & 1356 & 21,0 & 9,0 & 27,0 \\
\hline Ad. mineral & 100 & 80 & 160 & 440 & 160 & 5 & 1,26 & 2,1 & - & - & - & - \\
\hline
\end{tabular}

* Nutrientes que foram complementados devido à sua baixa concentração nos lodos de esgoto.

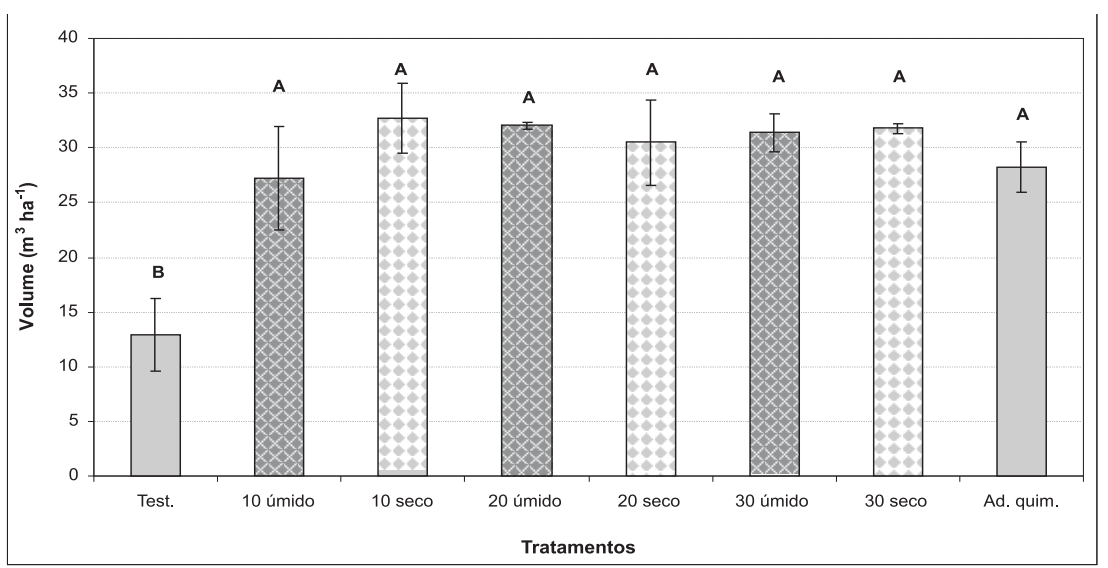

Figura 1 - Volume de madeira produzida pelos eucaliptos aos 18 meses de idade, nos diferentes tratamentos e respectivo desvio-padrão (letras iguais não diferem entre si, pelo teste de Duncan).

Figure 1 - Wood produced by the eucalypts, with 18 months old, in the different treatments and standard deviation (equal letters do not differ between itselffor the Duncan's test).

$\mathrm{Na}$ fase inicial de desenvolvimento, os eucaliptos dependem, em grande parte, dos nutrientes disponíveis no solo (GONÇALVES et al., 2000). Os resultados desta pesquisa demonstram que a menor dose de lodo de esgoto aplicada ao solo (10 $\left.\mathrm{t} \mathrm{ha}^{-1}\right)$, complementada com K e B, foi capaz de suprir a demanda nutricional. Esse fato havia sido preliminarmente observado neste experimento três meses após o plantio das mudas (POGGIANI, 2003). O resultado comprova, portanto, que a aplicação do lodo diretamente nas linhas de plantio disponibiliza rapidamente os nutrientes necessários para o desenvolvimento das mudas, podendo substituir a adubação mineral convencional, geralmente praticada pelas empresas florestais. Esse aspecto torna-se relevante, em comparação com o resultado obtido por Guedes (2000), que também constatou o efeito positivo do lodo de esgoto produzido na ETE de Barueri (tratado com cal e cloreto férrico) sobre o crescimento dos eucaliptos, mas apenas 10 meses após sua aplicação nas entrelinhas de plantio. A partir dessa constatação, Guedes (2000) sugeriu, então, que deveria ser mantida a adubação mineral de base, visando estimular o crescimento inicial das árvores tratadas com lodo de esgoto aplicado nas entrelinhas.

Nesta pesquisa, entretanto, foi comprovada a melhor opção de se aplicar o lodo nas linhas de plantio, levando em conta o volume de madeira produzido aos 18 meses de idade (Figura 1), que foi superior a $30 \mathrm{~m}^{3}$ por hectare em quase todos os tratamentos. Comparativamente, Guedes e Poggiani (2003) obtiveram, também aos 18 meses de idade, nos tratamentos com doses crescentes de biossólido úmido tratado com cal, mas aplicado nas entrelinhas de plantio, um volume de madeira variando entre 15 e $20 \mathrm{~m}^{3}$ por hectare.

R. Árvore, Viçosa-MG, v.32, n.5, p.845-854, 2008 
Na Austrália, em plantio experimental de eucaliptos irrigado com efluente proveniente de estação de tratamento de esgoto, observaram uma produção de $64 \mathrm{~m}^{3}$ por hectare, aos 34 meses de idade (POLGLOSE e MYERS, 1995). Entretanto, deve ser considerado que neste caso, além da adição de nutrientes, houve aporte adicional de água, fator importante no crescimento dos eucaliptos, principalmente em regiões de baixa precipitação. De maneira geral, os resultados observados neste experimento, aos 18 meses de idade, evidenciam que tanto o biossólido seco quanto oúmido, complementados com $\mathrm{Ke} \mathrm{B}$, poderiam substituir satisfatoriamente a adubação mineral. Visualmente, observou-se também que as parcelas experimentais dos eucaliptos, tratadas com lodo de esgoto, apresentaram o fechamento mais rápido das copas em relação aos tratamentos-testemunha e com adubo mineral, o que poderá gerar redução de custos no controle das plantas invasoras.

\subsection{Efeito das doses crescente de biossólidos na concentração de nutrientes nas folhas}

A aplicação das doses de lodo de esgoto, complementado com $\mathrm{K} \mathrm{e} \mathrm{B}$, refletiu-se nos teores de macro e micronutrientes das folhas, aos 18 meses de idade (Tabela 4). O aproveitamento dos nutrientes adicionados via adubo mineral ou orgânico depende das condições climáticas sazonais e do momento em que ocorre o fechamento das copas do povoamento, quando nas árvores passa a prevalecer a transferência interna dos nutrientes através do ciclo bioquímico (GONÇALVES et al., 2000). Nas Tabelas 4 e 5 são apresentados os resultados das concentrações de macro e micronutrientes nas folhas dos eucaliptos submetidos aos diferentes tratamentos. As concentrações de diversos elementos foram afetadas, principalmente, nos tratamentos com as doses mais elevadas de lodo de esgoto. Observaram-se aumento nas concentrações de P, Ca e Zn nas folhas e, inversamente, diminuição de Mn com o aumento nas doses dos biossólidos. Guedes e Poggiani (2003) observaram resultados semelhantes na nutrição foliar de eucaliptos tratados com lodo de esgoto (biossólido) aplicado nas entrelinhas de plantio entre 2 e 18 meses de idade. Esses autores verificaram que os eucaliptos, tratados com a adição de biossólido ao solo, apresentaram teores foliares de N, P, Ca e S mais elevados e teores mais baixos de $\mathrm{Mg}$ e $\mathrm{Mn}$ em relação ao tratamento com adubação mineral. O N apresenta apenas tendência de aumento da concentração foliar nos tratamentos com as doses mais elevadas de biossólido. Entretanto, em função da variação dos resultados analíticos entre os diferentes blocos, as diferenças não foram significativas. Todavia, as concentrações de $\mathrm{N}$ observadas em todos os tratamentos com lodo estão acima dos valores máximos indicados para as concentrações foliares em eucaliptos cultivados em vários locais no Estado de São Paulo (BELLOTE e SILVA, 2000). Nesta pesquisa, as análises foliares foram realizadas aos 18 meses de idade, ou seja, seis meses após a fase de fechamento das copas, e nessa fase tende a diminuir a demanda por nutrientes do solo em virtude da otimização do ciclo bioquímico (MILLER, 1981), sendo cada vez menor a resposta das árvores à fertilização mineral após o fechamento das copas (GONÇALVES et al., 2000). Análises realizadas preliminarmente em eucaliptos dessa área experimental aos 10 meses de idade apresentaram concentrações foliares de $\mathrm{N}$, variando entre 29 e $35 \mathrm{~g} \mathrm{~kg}^{-1}$, conforme as doses de biossólidos aplicadas (POGGIANI, 2004). Foram, portanto, superiores às observadas aos 18 meses de idade. Na Espanha também foi observado maior incremento volumétrico em experimentos com pinheiros tratados com doses crescentes de lodo de esgoto (EGIARTE et al., 2005). Entretanto, a concentração de $\mathrm{N}$ observada nas acículas foi maior nas árvores do tratamento-testemunha do que nos tratamentos com adição de lodo. Os referidos autores atribuíram esse resultado ao efeito de diluição do $\mathrm{N}$ na biomassa produzida em maior quantidade nos talhões de pinheiros adubados com lodo de esgoto.

Tabela 4 - Concentração foliar de macronutrientes nas folhas dos eucaliptos nos tratamentos: testemunha e adubação mineral convencional e nas doses crescentes de lodo de esgoto (úmido e seco)

Table 4-Foliar concentration of macronutrients in the leaves of eucalypts in the treatments: control, full mineral fertilization and in the incresing doses of wet and dry sludge

\begin{tabular}{lcccccc}
\hline Tratamentos & $\mathrm{N}$ & $\mathrm{P}$ & $\mathrm{K}$ & $\mathrm{Ca}$ & $\mathrm{Mg}$ & $\mathrm{S}$ \\
\cline { 2 - 7 } & \multicolumn{5}{c}{$\mathrm{g} \mathrm{Kg}^{-1}$} \\
\hline Testemunha & $26,4 \mathrm{a}$ & $1,45 \mathrm{~b}$ & $3,4 \mathrm{~b}$ & $3,6 \mathrm{~b}$ & $2,0 \mathrm{~b}$ & $1,2 \mathrm{a}$ \\
10 úmido & $26,5 \mathrm{a}$ & $1,50 \mathrm{~b}$ & $5,2 \mathrm{a}$ & $3,6 \mathrm{~b}$ & $1,8 \mathrm{~b}$ & $1,0 \mathrm{a}$ \\
10 seco & $25,4 \mathrm{a}$ & $1,47 \mathrm{~b}$ & $4,6 \mathrm{a}$ & $4,1 \mathrm{ab}$ & $2,0 \mathrm{~b}$ & $1,1 \mathrm{a}$ \\
20 úmido & $28,5 \mathrm{a}$ & $1,70 \mathrm{a}$ & $4,9 \mathrm{a}$ & $4,3 \mathrm{ab}$ & $2,0 \mathrm{~b}$ & $1,2 \mathrm{a}$ \\
20 seco & $27,5 \mathrm{a}$ & $1,77 \mathrm{a}$ & $4,7 \mathrm{a}$ & $4,2 \mathrm{ab}$ & $2,0 \mathrm{~b}$ & $1,2 \mathrm{a}$ \\
30 úmido & $29,3 \mathrm{a}$ & $1,75 \mathrm{a}$ & $4,4 \mathrm{a}$ & $5,2 \mathrm{a}$ & $2,1 \mathrm{~b}$ & $1,3 \mathrm{a}$ \\
30 seco & $28,5 \mathrm{a}$ & $1,93 \mathrm{a}$ & $4,4 \mathrm{a}$ & $4,5 \mathrm{ab}$ & $2,0 \mathrm{~b}$ & $1,3 \mathrm{a}$ \\
Adubação & $24,0 \mathrm{a}$ & $1,30 \mathrm{~b}$ & $4,9 \mathrm{a}$ & $4,8 \mathrm{a}$ & $2,5 \mathrm{a}$ & $1,2 \mathrm{a}$ \\
mineral & & & & & & \\
\hline
\end{tabular}

* Médias com letras iguais não diferem entre si pelo teste de Duncan (5\%). 
O fósforo também foi suprido ao solo dos diferentes tratamentos com a adição do lodo, em doses variando de 327 a $1.152 \mathrm{~kg} \mathrm{ha}^{-1}$ de $\mathrm{P}_{2} \mathrm{O}_{5}$. Esse elemento é um dos nutrientes mais importantes para o crescimento dos eucaliptos, principalmente em solos arenosos de baixa fertilidade, visto que sua carência gera limitações severas no desenvolvimento das mudas. Observou-se efeito positivo das doses de lodo de esgoto nas concentrações de fósforo encontradas nas folhas, variando de 1,45 a 1,93 $\mathrm{g} \mathrm{kg}^{-1}$. Resultados semelhantes foram verificados por Guedes e Poggiani (2003) em parcelas experimentais de eucaliptos tratados com biossólido úmido, respectivamente aos 20 e 56 meses de idade. A menor concentração foliar de P, observada no tratamento com adubação mineral, pode ser atribuída à rápida fixação do $\mathrm{P}$ mineral adicionado ao solo via adubo, associada também ao efeito da diluição do $\mathrm{P}$ na maior quantidade de biomassa produzida nesse tratamento (GONÇALVES et al., 2000). Foi verificado, ainda, que as concentrações de $\mathrm{P}$ nas folhas dos eucaliptos avaliados neste experimento foram, em média, 30\% superiores às observadas por Guedes e Poggiani (2002) com as mesmas doses de lodo aplicadas. Esse resultado pode ser atribuído à colocação do lodo diretamente nas linhas de plantio, que possibilitou a quase imediata disponibilização do $\mathrm{P}$ para o sistema radicular das mudas. Do ponto de vista operacional, a adição do lodo de esgoto nas linhas de plantio representa ganho em relação à disposição nas entrelinhas, visto que as raízes das mudas demoram alguns meses para alcançar o local dos nutrientes na aplicação de lodo na entrelinha (GUEDES, 2005).

Observou-se, ainda, resposta significativa na concentração foliar do cálcio (Tabela 4), principalmente nos tratamentos com as maiores doses de lodo e também no tratamento com adubo mineral, em que foi aplicada a calagem. No entanto, as concentrações de cálcio nas folhas dos eucaliptos deste experimento, em que foi utilizado lodo esgoto tratado com polieletrólito, foram sempre inferiores às concentrações encontradas por Guedes e Poggiani (2003), que aplicaram biossólido úmido tratado com cal (carbonato de cálcio), apresentando uma concentração de $95 \mathrm{~g} \cdot \mathrm{kg}^{-1}$ de cálcio.

As concentrações de $\mathrm{Mg}$ foram estatisticamente similares nos tratamentos com aplicação de lodo e no tratamento-testemunha, porém inferiores aos valores obtidos no tratamento com adubação mineral $\left(2,5 \mathrm{~g} \mathrm{~kg}^{-1}\right)$, devido à calagem prévia aplicada nesse tratamento.

Nos teores foliares de $\mathrm{S}, \mathrm{Cu}$ e Fe, não foram observadas diferenças significativas entre os tratamentos. Esses resultados podem ser atribuídos à maior diluição dos elementos na biomassa dos eucaliptos tratados com lodo e adubo mineral e pela capacidade das árvores em manter certo equilíbrio entre os teores desses nutrientes nas folhas, mesmo havendo maior disponibilidade dos elementos no solo.

A complementação com K e B nos tratamentos com lodo de esgoto apresentou-se eficaz, pois os valores das concentrações foliares foram significativamente superiores aos da testemunha e similares à adubação mineral. A concentração de potássio no lodo de esgoto é baixa, visto que esse elemento é altamente solúvel em água, sendo perdido no efluente líquido durante o tratamento (TSUTIYA, 2001). O mesmo efeito acontece em relação ao boro, que é solubilizado. A necessidade de complementação com B ocorre por ser este um micronutriente importante para o desenvolvimento das plantas, mas que em dosagem elevada pode tornar-se tóxico, sobretudo para o eucalipto (NOVELINO et al., 1982).

Tabela 5 - Concentração foliar de micronutrientes nas folhas dos eucaliptos nos tratamentos: testemunha e adubação mineral convencional e nas doses crescentes de lodo de esgoto (úmido e seco)

Table 5 -Foliar concentration of micronutrients in the leaves of eucalypts in the treatments: control, full mineral fertilization and in the increasing doses of wet and dry sludge

\begin{tabular}{lccccc}
\hline Tratamentos & $\mathrm{B}$ & $\mathrm{Cu}$ & $\mathrm{Fe}$ & $\mathrm{Mn}$ & $\mathrm{Zn}$ \\
\cline { 2 - 6 } & \multicolumn{5}{c}{$\mathrm{mg} \mathrm{Kg}^{-1}$} \\
\hline Testemunha & $13,5 \mathrm{~b}$ & $10,3 \mathrm{a}$ & $135,0 \mathrm{~b}$ & $820,0 \mathrm{a}$ & $8,3 \mathrm{~b} \mathrm{c}$ \\
10 úmido & $37,3 \mathrm{a}$ & $9,3 \mathrm{a}$ & $137,0 \mathrm{~b}$ & $519,0 \mathrm{~b}$ & $8,3 \mathrm{~b} \mathrm{c}$ \\
10 seco & $44,0 \mathrm{a}$ & $9,7 \mathrm{a}$ & $163,0 \mathrm{ab}$ & $570,0 \mathrm{~b}$ & $8,0 \mathrm{~b} \mathrm{c}$ \\
20 úmido & $35,0 \mathrm{a}$ & $10,3 \mathrm{a}$ & $152,0 \mathrm{ab}$ & $417,7 \mathrm{~b}$ & $11,7 \mathrm{a} \mathrm{b}$ \\
20 seco & $35,5 \mathrm{a}$ & $8,7 \mathrm{a}$ & $137,7 \mathrm{~b}$ & $445,7 \mathrm{~b}$ & $8,0 \mathrm{~b} \mathrm{c}$ \\
30 úmido & $39,7 \mathrm{a}$ & $9,0 \mathrm{a}$ & $173,7 \mathrm{a}$ & $537,7 \mathrm{~b}$ & $14,3 \mathrm{a}$ \\
30 seco & $41,0 \mathrm{a}$ & $10,3 \mathrm{a}$ & $139,7 \mathrm{~b}$ & $381,0 \mathrm{~b}$ & $11,3 \mathrm{a} \mathrm{b}$ \\
Ad. mineral & $34,0 \mathrm{a}$ & $9,5 \mathrm{a}$ & $159,0 \mathrm{ab}$ & $488,3 \mathrm{~b}$ & $6,0 \mathrm{c}$ \\
\hline
\end{tabular}

* Médias com letras iguais não diferem entre si pelo teste de Duncan.

R. Árvore, Viçosa-MG, v.32, n.5, p.845-854, 2008 
Com relação ao zinco, verificou-se o aumento de sua concentração nas folhas com as maiores doses de lodo aplicadas ao solo. Nos lodos produzidos na ETE de Barueri, observou-se que os teores desse elemento variavam entre 0,32 e $0,24 \%$, sendo sua presença atribuída à atividade de indústrias, que despejam seus efluentes no sistema de esgoto doméstico. O zinco, sendo um metal pesado, necessita de monitoramento adequado quando aplicado em excesso nos ecossistemas agroflorestais. Neste experimento, verificou-se, entretanto, que sua concentração nas folhas dos eucaliptos não ultrapassou o valor de $15 \mathrm{mg} \mathrm{kg}^{-1}$, mesmo nas doses mais elevadas de lodo aplicadas. Segundo Bellote e Silva (2000), essa concentração pode ser considerada como normal em plantios comerciais de eucaliptos. É possível que o excesso de zinco contido no lodo de esgoto seja imobilizado na matéria orgânica do solo e também estocado no sistema radicular das árvores.

Em relação ao Mn, observou-se tendência de diminuição dos teores nas folhas dos eucaliptos em relação às doses crescentes de lodo de esgoto aplicadas. Entretanto, os resultados não foram estatisticamente diferentes. A menor concentração nas folhas pode ser atribuída ao aumento do $\mathrm{pH}$ do solo (TSADILAS et al., 1995; CHRISTIE et al., 2001; GUEDES e POGGIANI, 2003) devido ao efeito do lodo, que promove a precipitação do $\mathrm{Mn}$, tornando-o menos disponível às plantas, e esse efeito pode ser considerado benéfico para os eucaliptos (GUEDES e POGGIANI, 2003). Geralmente, no Brasil não são observados problemas de deficiência de Mn nas culturas de eucaliptos. Mas, contrariamente, pode haver excesso desse elemento, gerando toxicidade às plantas, pois em várias regiões do Estado de São Paulo observou diminuição da produtividade em sítios com excesso de Mn (SGARBY, 2002).

\section{CONCLUSÕES}

1. A aplicação dos lodos de esgoto úmido e seco nas linhas de plantio, complementados com K e B, incrementou significativamente o volume de madeira produzida pelos eucaliptos, servindo como fonte de nutrientes.

2. O uso do lodo de esgoto permitiria a substituição das adubações nitrogenada e fosfatada, além da adição dos micronutrientes (exceto B).

R. Árvore, Viçosa-MG, v.32, n.5, p.845-854, 2008
3. O lodo de esgoto seco (granulado) aplicado ao solo das parcelas experimentais não afetou o volume de madeira produzido aos 18 meses de idade em relação ao lodo úmido (torta).

4. A aplicação dos lodos de esgoto, complementados com $\mathrm{K}$ e B, afetou positivamente a concentração dos elementos $\mathrm{P}, \mathrm{K}, \mathrm{Ca}, \mathrm{B}$ e Zn nas folhas e negativamente a concentração de $\mathrm{Mn}$.

\section{REFERÊNCIAS}

BELlote, A. F. J.; SILVA, H. D. Técnicas e amostragens e avaliações nutricionais em plantios de Eucalyptus spp. In: GONÇALVES, J. L. M.; BENEDETTI, V. (Eds.) Nutrição e fertilização florestal. Piracicaba: IPEF, 2000. p.106-136.

CHRISTIE, P. et al. Agronomic value of alkaline-stabilized sewage biosolids for spring barley. Agronomy Journal, v.93, n.1, p.144-151, 2001.

EGIARTE, G. et al. Effect of repeated applications of sewage sludge on the fate of $\mathrm{N}$ in soils under Monterey pine stands. Forest Ecology and Management, v.216, n.1/3, p.257-269, 2005.

FJÄLLBORG, B. et al. Identification of metal toxicity in sewage sludge leachate.

Environment International, v. 31, n.1, p.25-31, 2005.

FORSTER, L. J.; LOGAN, R. H.; MILLER WHITE, R. K. State of the art in municipal sewage sludge landspreading. In: LOEHR, R. C. (Ed.) Land as a waste management alternative. Ann Arbor: Science Publishers, 1977. p.603-618.

GATTO, A. et al. Efeito do método de preparo do solo, em área de reforma, nas suas características, na composição mineral e na produtividade de plantações de Eucalyptus grandis. Revista Árvore, v.27, n.5, p.635-646, 2003.

GUEDES, M. C., POGGIANI, F. Variação dos teores de nutrientes foliares em eucalipto fertilizado com biossólido. Scientia

Forestalis, v.63, p.188-201, 2003. 
GUEDES, M. C. Efeito do lodo de esgoto (biossólido) sobre a nutrição, ciclagem de nutrientes e crescimento de subbosque, em plantação de eucalipto. 2000. 74f. Dissertação (Mestrado em Recursos Florestais) - Escola Superior de Agricultura "Luiz de Queiroz", Piracicaba, 2000.

GUEDES, M. C. Ciclagem de nutrientes após aplicação de lodo de esgoto (biossólido) sobre Latossolo cultivado com Eucalyptus grandis. 2005. 154f. Tese (Doutorado emRecursos Florestais) - Escola Superior de Agricultura "Luiz de Queiroz", Piracicaba, 2005. 154p.

GONÇALVES, J. L. M. et al. Reflexos do cultivo mínimo e intensivo do solo em sua fertilidade e na nutrição das árvores. In: GONÇALVES, J. L. M.; BENEDETTI, V. (Eds.) Nutrição e fertilização florestal. Piracicaba: IPEF, 2000. p.3-55.

KIMBERLEY, M. O. A. et al. Economic analysis of growth response from a pine plantation forest applied with biosolids. Forest Ecology and Management, v.189, n.1/3, p.345-351, 2004.

LUDUVICE, M. Experiência da companhia de saneamento do distrito federal na reciclagem agrícola de biossólido. In: BETTIOL, W.;

CAMARGO, O. A. (Eds) Impacto

ambiental do uso agrícola do lodo de esgoto. Jaguariúna: Embrapa Meio Ambiente, 2000. p.153-162.

MALAVOLTA, E.; VITTI, G. C.; OLIVEIRA, S. A. Avaliação do estado nutricional das plantas: princípios e aplicações. Piracicaba: Potafos, 1997. 319p.

MCNAB, W. H.; BERY, C. R. Distribution of aboveground in three pine species planted on a devasted site amended with sewage sludge or inorganic fertilizer. Forest Science, v.31, n.2, p.373-382, 1985.

NOVELINO, J. O. et al. Efeito de níveis de boro em solução nutritiva no crescimento de Eucalyptus spp. Revista Árvore, v.6, n.1, p.45-51, 1982.
POLGLASE, P. J.; MYERS, B. J. Tree plantation for recycling effluent and biosolids in Australia. In: ELDRIDGE, K. G.; CROWE, M. P.; OLD, K. M. (Eds.) Environmental management: The role of Eucalypts and other fast growing species.

Proceedings of the Joint AustralianJapanese Workshop. Canberra, CSIRO, 1995.p.100-109,

POGGIANI, F.; GUEDES, M. C.; BENEDETTI, V. Aplicabilidade de biossólido em plantações florestais: I. reflexo no ciclo dos nutrientes. In: BETTIOL, W.; CAMARGO, O. A. (Eds) Impacto ambiental do uso agrícola do lodo de esgoto. Jaguariúna: Embrapa Meio Ambiente, 2000. p.163-178.

POGGIANI, F. Uso de biossólidos produzidos nas estações de tratamento de esgoto da região metropolitana de São Paulo em plantações florestais. Piracicaba: FEALQ/SABESP, 2003. 93p. (Relatório Técnico-Científico, 12)

POGGIANI, F. Uso de biossólidos produzidos nas estações de tratamento de esgoto da região metropolitana de São Paulo em plantações florestais. Piracicaba: FEALQ/SABESP, 2004. 69p. (Relatório Técnico-Científico, 18)

POGGIANI, F. Uso de biossólidos produzidos nas estações de tratamento de esgoto da região metropolitana de São Paulo em plantações florestais. Piracicaba: FEALQ/SABESP, 2005. 68p. (Relatório Técnico-Científico, 36)

ROCHA, G. N. Monitoramento da

fertilidade do solo, nutrição mineral e crescimento de um povoamento de Eucalyptus grandis fertilizado com biossólido. 2002. 48f. Dissertação (Mestrado em Recursos Florestais) - Escola Superior de Agricultura "Luiz de Queiroz", Piracicaba, 2002.

SELIVANOVSKAYA, S. Y.; LATYPOVA, V.Z; ARTAMONOVA, L. A Use of sewage sludge compost as the restoration agent on the degraded soil of Tatarstan Journal of Environmental Science and Health Part A, v.38, n.8, p.1549-1556, 2003.

R. Árvore, Viçosa-MG, v.32, n.5, p.845-854, 2008 
SGARBY, F. Produtividade de Eucalyptus sp. Em função do estado nutricional e da fertilidade do solo em diferentes regiões do estado de São Paulo. 2002. 101f. Dissertação (Mestrado em Recursos Florestais) - Escola Superior de Agricultura “Luiz de Queiroz”, Piracicaba, 2002.

TSADILAS, C. D. et al. Influence of sewage sludge application on soilproperties and on tha distribution and availability of heavy metal fractions.

Communication Soil Science and Plant Analisys, v.26, n.15/16, p.2603-2619, 1995.
TSUTYA, M. T. Alternativas de disposição final de biossólidos gerados em estações de tratamento de esgoto. In: BETTIOL, W.; CAMARGO, O. A. (Eds) Impacto ambiental do uso agrícola do lodo de esgoto. Jaguariúna: Embrapa Meio Ambiente, 2000. p.69-106.

VAZ, L. S. V. Crescimento inicial, fertilidade do solo e nutrição de um povoamento de Eucalyptus grandis fertilizado com biossólido. 2000. 41f.

Dissertação (Mestrado em...) - Escola Superior de Agricultura “Luiz de Queiroz", Piracicaba, 2000. 